\title{
The Spacial Construction of Cultural Tourism of Fuzhou Based on Pole-axis System Theory
}

\author{
Wenping Xiong \\ Nanchang Normal University \\ Nanchang Jiangxi 330029
}

\begin{abstract}
Based on pole-axis system theory, important nodes and developing axis of cultural tourism in Fuzhou are selected.It aims to optimize the spatial structure for the cultural tourism in Fuzhou to realize the sustainable development of tourism industry.
\end{abstract}

Keywords-the pole-axis system; cultural tourism; spacial construction; Fuzhous

\section{INTRODUCTION}

The academician of Chinese Academy of Sciences, Mr. Lu Dadao, came up with the "Pole - Axis system" theory, where the pole stands for center place i.e. center town at various level, being gathering place of district at various level, while the axis refers to the infrastructure clusters linked by trunk line of transportation, telecommunication, energy transmission line and trunk line of water sources[1]. When Mr. Lu Yulin discussed the scientific connotation of the pole and axis system theory, he pointed out the axis of the pole and axis system refers to linking some center towns at different level in a certain direction to form a relatively concentrated population and industrial belt. As the axial line and its surrounding area have already had strong economic strength and still have large development potential, the axial line can also be called as "development axial line" or "developing axial line" [2].

Fuzhou city of Jiangxi province, named Linchuan county in history, has had the good reputation of "the birth place of talent" and "district of culture", where a large group of historical cultural celebrities such as Wang Anshi, Zheng Gong, Tang Xianzhu, Yan Shu and Lu Xiangshan came from; the education of Fuzhou is famous all over China, having become the famous brand in the national educational circle, where lots of students from other places of China study in Fuzhou; Fuzhou has been named as "Hometown of opera" in history, being the hometown of Tang Xianzhu, the eastern Shakespeare; the Nanfeng dance of Fuzhou is honored as the living fossil of the ancient dance, being the famous town of Chinese folk art; Fuzhou is the home where the Red Army lived, being the main battle yard of the fourth and fifth counter-campaigns of the Red Army; the religion activity sites of Fuzhou are all over the area; Fuzhou is "Hometown of Chinese oranges", "Hometown of Chinese watermelon", "Hometown of Chinese white lotus", "Hometown of Ma chicken", with clear agricultural characteristics and lots of types.
Therefore, based on the pole - axis theory, this paper discusses the pole and axis development for Fuzhou cultural tourism according to the spatial distribution map of Fuzhou cultural tourism resources and transportation condition in Fuzhou city, using the axial line to connect the nodes for grouping and joint action, in order to optimize the spatial structure of Fuzhou cultural tourism, and enrich the content of the pole - axis theory in the spatial development of Fuzhou cultural tourism, and construct the best spatial development grid of Fuzhou cultural tourism.

\section{KEY NODES OF TOURISM DEVELOPMENT}

Under the comprehensive consideration of the city's radiating ability, comprehensive strength, tourism resources feature, transportation facility and so on, four levels of development nodes of Fuzhou cultural tourism (growth pole) can be determined. Linchuan district is the political, cultural and economic center of Fuzhou, and showcase of the opening-up to outside, and it is the county and district with the strongest comprehensive strength and the most frequent relation to the outside of the whole Fuzhou, featured of celebrity and talent culture, opera culture and education culture. Out of these important position and advantageous condition, Linchuan district is chosen to be the class 1 node for Fuzhou cultural tourism development in aspect of regional tourism. It can be seen from the class of Fuzhou cultural tourism resources that, most distributions of high class tourism resources are in Nanfeng county, Le'an county and Zixi county, in which Nanfeng has 4 spots of national class, 5 spots of provincial class; Le' an county has 2 spots of national class, 8 spots of provincial class; Zixi county has 2 spots of national class and 3 spots of provincial leve[5]. Among the tourism spots of the three counties, Le'an Liukeng ancient village (State key historic reservation zone), Nanfeng dance (State intangible cultural heritage), and Zixi Dajiueshan (State 4A scenic spots) are the representatives. Tourism resources of Nanfeng county, Le'an county and Zixi county are rich, with clear characteristics. The communication condition of Nanfeng County and Zixi County is relatively good; Le'an County will be improved in terms of communication along with the construction of $\mathrm{Fu} \mathrm{Ji}$ expressway. Therefore, Nanfeng county, Le'an county and Zixi county are chosen as the class 2 nodes of tourism for Fuzhou cultural tourism development (growth point of tourism).The scenic spots of Liukeng ancient village, Jinshan temple, Dajueshan, Caoshansi, Fashui hot spring, Linchuan 
hot spring, Junfengshan, Magushan are tourism resources of good development condition and huge development potential of Fuzhou. So, the class 3 tourism growth point is mainly to choose from these top scenic spots. The class 4 tourism growth point is mainly from other main tourism resources with development potential.

\section{SELECTION OF IMPORTANT DEVELOPMENT AXIS}

According to the transportation facility and tourism resources condition of Fuzhou, the axis of tourism development connecting Fuzhou cultural tourism nodes is divided into three classes. The transportation line linking Linchuan district and Zixi County is chosen as class 1 development axis, which links the two important nodes with complementing and combination of the tourism resources, forming an important development belt. As national highway 316 is a transport trunk road linking Linchuan district with Zixi County, it becomes class 1 development axis of Fuzhou cultural tourism. Jinxi to Guangchang line and Linchuan to Lichuan line are chosen as class 2 development axis. Jinxi to Guangchang line links Jinxi County, Nancheng County, Nanfeng County, Guangchang County, where resources are rich. National highway 206 and Ji Guang expressway, Jingfu Expressway are class 2 development axis of Fuzhou cultural tourism. Dongxiang to Le'an line, Zixi to Lichuan to Nanfeng line, Nanfeng to Yihuang to Le'an line are listed as Level 3 development axis. Therefore, the provincial highway linking line of Dongxiang to Linchuan to Congren to Le'an, and line of Zixi to Lichuan to Nanfeng, and line of Nanfeng to Yihuang to Le'an is taken as class 3 development axis of Fuzhou cultural tourism.

In summary, the important nodes and important development axis are chosen to form the pole - axis development structure of Fuzhou cultural tourism. Constitution of the pole-axis development structure is beneficial to promoting the access of the tourism spots, so as to make various class tourism nodes of Fuzhou cultural tourism to play a radiation role of the axis by relying on the axis of transportation route, to form tourism network of Fuzhou culture, which diffuses each key elements of tourism to the surrounding area and will bring forward the whole Fuzhou tourism development accordingly.

\section{Spatial DeVElopment Measures of FuZHou CULTURAL TOURISM}

According to the overall thoughts of creating the core area while stressing the center town area; forming development corridors by relying on transportation and tourism centralized area; striving to develop key county area and scenic spots while consolidating the key points; forming development in network while constructing the four major tourism zones, three tourism gathering center and transport hubs will be formed by taking the center urban area of Fuzhou as the core area, and four major cultural tourism zones constructed by relying on the three major corridors formed from the centralized belt of transportation and tourism.

\section{A. One Core}

The core area is the central urban area of Fuzhou, which is the political, cultural and economic center of Fuzhou, and the showcase of opening-up of Fuzhou, having good locational conditions and convenient transportation condition, with important strategic locations. Due to such important locations and advantageous condition, the center urban area of Fuzhou is chosen as the core of Fuzhou cultural tourism development in aspect of regional tourism, to form a growth pole and bring its attractive force and radiating force into play. By the tourism development of the center urban area of Fuzhou, the whole Fuzhou cultural tourism can be brought to develop rapidly. The brand advantages of hometown of talents, hometown of opera and cradle of education shall be brought into full play. The Fuzhou center urban area shall be built to be a cultural carrier of Fuzhou according to thought of construction of ecological and cultural famous city, to fully expose its beautiful natural scenery, through transportation to build images of Fuzhou modern tourism, and establish its strategic position of Fuzhou cultural and ecological famous city.

\section{B. The Three Centers}

The three centers refer to the tourism gathering center of Linchuan district, Nancheng county and Dongxiang county and the transportation hub. Linchuan district will be constructed to be the regional comprehensive transportation center of Fuzhou, and Nancheng to be the regional comprehensive transportation center of Fuzhou, Dongxiang to be the regional comprehensive transportation hub of Fuzhou. Transportation network construction by water, air and land of tourism center areas shall be strengthened to connect the main source places of tourists. Functional construction of gathering, transit and liaison of the three major transportation hubs of Linchuan district, Nancheng county and Dongxiang county shall be strengthened, enhancing the convenience of tourists to enter Fuzhou city and access to all the scenic spots after coming in Fuzhou. Transportation construction of Linchun district shall be the first priority of the key transportation work, to build Linchuan city into the real class 1 center of transportation of Fuzhou, and Nancheng into the transportation hub of central part of Fuzhou, the hub of provincial level in east of Jiangxi province even in west of Fujian province; Dongxiang into the hubs to connect Nancheng, Yingtn and other cities, becoming the north gate to enter Fuzhou.

\section{The Three Corridors}

1) Basis of selection of the key axis. When this paper chooses the development axis for spatial structure of Fuzhou cultural tourism, area with good economic development is chosen; together with area rich and high level tourism resources, and good tourism development; and area of key transportation line. As area of good economic development has not only developed commercial culture, but also good infrastructure condition, and it is ideal place for shopping and recreation by itself, besides, it has radiating effect on the surrounding counties, having function of development axis. Tourism destination with good tourism development can 
make tourism become bigger and stronger to form tourism industry, while there area of tourism destination will become belt of tourism industry, with condensation and radiating effect, being an important development axis. Transport route is an important aspect for developing tourism, able to connect center place of tourism with the tourism destination. Important transport trunk lines can form beneficial location advantages, thus having function of development axis too.

2) The three corridors. The tourism development corridor along Jing $\mathrm{Fu}$ expressway passes through the core area, which is the Fuzhou cultural tourism development center. The corridor development shall take the core area as the center, to play fully the radiating effect of the core area, fully integrating the resources along Jing $\mathrm{Fu}$ expressway corridor. This development corridor takes cultural tour of celebrity and talent, opera, hot spring holiday, sight seeing and recreation as the development direction, forming tourism image of development corridor along Jing Fu expressway with protruding features.

Along the tourism development corridor along Ji Guang expressway, there gather: Magushan, Junfengshan and other famous mountain; celebrities like Lu Xiangshan, Zheng Gong; folk culture represented by Nanfeng dance and Guangchang Meng opera; and agricultural area of sightseeing represented by Nanfeng orange and Guangchang white lotus, and other rich resources. These have good quality and good combination, and this development corridor takes rural tour, sight-seeing and recreation tour, folk cultural tour, and celebrity and talent tour as the development direction, to actively bring advantages of $\mathrm{Ji}$ Guang expressway and National highway 206 into play, to quicken the supporting tour facility construction along the route, forming tourism image of corridor along $\mathrm{Ji}$ Guang expressway with protruding features.

The development corridor of tourism along $\mathrm{Zi} \mathrm{Yi} \mathrm{Li} \mathrm{line,}$ has road transportation and through national and provincial highway, where hold high level resources such as Dajueshan, Liukeng of ancient villages of 1000 years old, Caoshansi, Fashui hot spring, can form dense areas of tourism industry. This development corridor mainly takes religion culture tour, sight seeing and recreation, and ancient village culture tour as the development direction. The transportation of this corridor is not very convenient, so tourism transportation construction of the area shall be strengthen to form transport corridor crossing east and west of Fuzhou.

\section{The Four Zones}

Reasonable dividing of spatial function area of Fuzhou cultural tourism is an important step for developing Fuzhou cultural tourism. According to principle to stress the feature and key point, and care for others, the spatial function area of Fuzhou cultural tourism can be divided into the following four major cultural tourism zones according to principle of adjacent places, connected culture, similar resources, through transportation and correlation of markets.

1) North cultural tourism zone (tourism zone of culture of talent and opera) North cultural tourism zone can be called as tourism zone of culture of talent and opera. The north cultural tourism zone shall be built taking Linchuan district as the center, covering cultural tourism resources of Linchuan district, Jinxi County, Dongxiang County. This zone has thick sedimentation of history and culture, many cultural relics and historic sites, especially for talent culture, opera culture and education culture, which have large effects at home and abroad, having resources gifted for developing tourism with tourist from oversea. Therefore, this zone occupies a core position in Fuzhou cultural tourism. The main tourism resources are Wang Anshi Memorial, Wenchang Bridge, Fuzhou hall, Wang Anshi home, Shupu Street, Fuzhou cultural park, Linchuan hot spring, Jinshansi temple, Shushansi temple and so on, forming the cultural tourism featuring the talent culture, opera culture and religion culture. Its tourism development shall take celebrity home tour, opera and folk customs tour, education cradle tour and hot spring tour as the development direction. The tourism function is positioned in: historic cultural study, recreation, religion praying first, and education tour and rural tour second, focusing on development and construction of Niyantai, Wenchangge, Xinglu Academy, Banshan Academy, Fuzhou educational park and other cultural scenery, strengthening their tourism function and enriching their culture connotation. Meanwhile, bringing brand effects of celebrity and talent culture into play, to combine with beautiful natural scenery, tourism activity of various types can be developed.

2) East cultural tourism zone (ecological and red culture tourism zone). The ecological and red culture tourism zone mainly includes the three counties of Nancheng county, Zixi county, Lichuan county. This zone is the area that embodies Fuzhou scenery the most. Its ecological environment is pretty primitive, with lots of waterfall and streams, and good covering of plantation on the mountain slope, especially the forest covering rate of Zixi County is as high as $87 \%$. The mian tourism resources are Magushan scenery area, Dajueshan scenery area, Matoushan national natural conservation area, Hongmen reservoir, Fashui hot spring, Ship-shaped ancient house, lake hot spring, new moon ancient village of minority, old site of Soviet government of Fujian and Jiangxi province, bridge of 10 thousand years and so on. The zone belongs to Fuzhou forestry economic area, being an advantageous area for developing modern tourism due to its good ecologic scenery. Therefore, this zone is suitable for developing recreational sight seeing, patriotic education for the first and scientific exploration and education, physical exercise for the second; the flagship brand for tourism shall be Dajueshan scenic spots and Magushan scenic spots and other landscape tours and red soil tour represented by the old Soviet government of Fujian and Jiangxi province.

3) South cultural tourism zone (agricultural culture tourism zone).South cultural tourism zone is also called agricultural culture tourism zone, covering Nanfeng and Guangcheng county, located in south of Fuzhou, having rich natural and cultural resources, and the main tourism resources are Nanfeng orange ecological sightseeing part, Lotus belt of 100 miles, Nanfeng dance, Junfengshan, Zixiaoxi stream drifting, Zheng Gong memorial and so on. 
The zone has rich and high level tourism resources, featuring specialized agriculture, folk culture and so on. Nanfeng and Guangchang are close in location, both with national highway 206 and Ji Guang expressway passing through, with similar resources, which can produce scale effects. This tourism zone plays an important role in Fuzhou tourism. The main content of tourism of the zone is: sightseeing agriculture park, folk culture, ecological sightseeing. The main orientation of the tourism function is, agricultural sightseeing, folk culture for the first and recreational amusement, historic cultural study for the second. The flagship brand of tourism is the agricultural culture represented by Nanfeng orange and Guangchang white lotus, and folk culture represented by Nanfeng dance.

4) West cultural tourism zone (religion ancient village culture tour zone).West cultural tourism zone is also called as the religion ancient village culture tour zone. The religion ancient village culture tour zone mainly includes Le'an, Yihuang and Congren. The main tourism resources of the zone are: Liukeng ancient village, Caoshansi temple, Tanlun tomb, Dongyu tomb, Guzhanglin, Xiatong waterfall group, Tangyin ancient town and so on.

Liukong of "the first village in history", is well known home and broad due to its completely reserved ancient building group in Ming and Qing Dynasty, and imperial examination culture, having been listed in the national key cultural relic conservation unit and the first group of national famous villages of historic culture, having extremely high development value. Caoshansi temple has a certain impact nationwide, absorbing lots of domestic and oversea tourists. This zone is featured with ancient village and religion resources, forming the tourism products such as historic sites, religion praying and recreation holiday spending. For this zone, the key development lies on the ancient village and town, religion culture and other tourism production. The tourism content of the zone is mainly: ancient village and town and tree, temples, river and lake and waterfall, tomb of celebrities. The main positioning of tourism function is, religion praying, roots seeking, historic culture research, and then recreation amusement, agriculture sightseeing. The tourism flagship and brand shall be the ancient culture represented by Liukeng ancient village, and religion culture represented by Caoshansi temple.

\section{CONCLUSION}

The "Pole - axis system" theory application in the spatial structure of Fuzhou cultural tourism, is beneficial for the high-efficiency distribution of cultural tourism nodes and axial line of Fuzhou, which will highlight effectively the key point while considering the whole situation, and the specialized staggered development, for handling the relations between balanced and unbalance d development of Fuzhou cultural tourism scientifically; beneficial for optimizing Fuzhou cultural tourism spatial development structure, constructing the famous cultural tourism destinations of Jiangxi, in order to realize the sustainable development of Fuzhou cultural tourism industry.

\section{REFERENCES}

[1] Mechanism analysis on the formation of "Pole - axis" spatial structure system by Lu Dadao, [J], Science of Geography, 2002, 22 (1)

[2] Retrospect and prospect on study of China regional spatial structure by Lu Yulin [J], Progress in Geography, 2002(7)

[3] Integration and development research on Fuzhou cultural tourism product by Xiong Wenping [J], Journal of Jiangxi Education College, 2012(1)

[4] Statistical yearbook of Jiangxi [M], China Statistics Press, 2011. 